\title{
Assessment of the Quality of the Environment in Duhok Province, Kurdistan Region of Iraq
}

\author{
Amina Jamil Muhammed ${ }^{1}$, Hazhir Karimi ${ }^{1, *}$, Berivan Karam Gharab ${ }^{1}$, Sevar Neamat ${ }^{2}$, Karamreza Mirzaei $^{3}$ \\ I* Department of Environmental Science, Faculty of Science, University of Zakho, Kurdistan Region of Iraq, \\ aminabamarni@gmail.com, hazhir.karimi@uoz.edu.krd, berivan.91301336@stud.uoz.edu.krd, \\ ${ }^{2}$ Department of Mechanical Engineering, College of Engineering, University of Zakho, Kurdistan Region-Iraq, \\ sevar.dilkhaz@uoz.edu.krd \\ ${ }^{3}$ Department of Social Science, Faculty of Basic Education, University of Zakho, Kurdistan Region of Iraq mirzai.kr@gmail.com
}

\begin{abstract}
Analyzing the quality of the environment is essential because it directly affects public health status and plays a significant role in the quality of life. This research aimed to evaluate the environmental quality of human-made factors in Duhok province using available data and geographic information systems. Population density, solid waste generation, and the location and density of the industrial units were considered and evaluated as the main anthropogenic factors affecting the quality of the environment in the study area. The overall result indicated that $28 \%$ and $58 \%$ of the study area has a moderate and high-quality state (suitable level), respectively. While low and very low classes involved only $14 \%$ (unsuitable level) mostly found in the southern regions and the province's capital. However, the low portion of the unsuitable situation highlighted this point that the province's capital and other main cities such as Zakho, Akre, and Semel had inappropriate environment quality and should be taken into more consideration. The integrated analysis of the environmental quality in Duhok province would increase the protection of the ecological environment and help the regional sustainable development and improvement of the quality of the environment.
\end{abstract}

Keywords: Environmental quality, environmental indicators, GIS, Duhok

Received: June 182020 / Accepted: August 282020 / Online: August 302020

\section{INTRODUCTION}

Environmental quality is a measure of the state of the environment affected by various conditions [1],[2]. Environmental quality refers to both the natural and built environment. It means not just the natural environment features such as water resources, climate conditions, natural disasters, and biodiversity but also human-made factors like population, traffic, and industry affect the quality of the environment [3],[4]. Discovering the quality of the environment is essential because it directly affects public health status and plays a significant role in the quality of life [4], [5].

GIS has widely been used for environmental studies such as land suitability, land use, and land cover changes, and ecological capability evaluation. In a study by [6], GIS was applied to residential simulation construction and land use modeling for the Netherlands. [1] combined GIS and remote sensing (RS) to evaluate the ecological state by multiple factors. [7] used GIS-based multi-criteria evaluation for assessing the potential of the human state and air quality in Isfahan Province in Iran. [8],[9] analyzed the risk of landslide using GIS in the Xiaojiang watershed. Karimi et al. (2018) and Kourosh Niya et al. (2019) used GIS, and remote sensing for land use/land cover change detection and modeling in Iran [10, 11], and some researchers used GIS for land suitability analysis such as site selection of solid waste landfill $[12,13]$.

This research aimed to evaluate the environmental quality affecting by human-made criteria in Duhok province using GIS and a multi-factor analysis approach. More specifically, based on human factors, including population density, solid waste generation, and industrial unit density, a state of the human environment was provided and quantified in the GIS environment. The required data and information were collected from government bodies and field checks and were analyzed in GIS. In this paper, the case study, methods, results, discussion, and conclusion are described in detail.

\section{CASE STUDY}

The case study in this study is Duhok Province, located in the north of the Kurdistan Region (Fig. 1). The population of Duhok province is approximately 1.3 million and it includes seven districts (counties), including Duhok, Semel, Zakho, Amedy, Sheikhan, Akre, and Bardarsh, where Duhok city is the capital of the province. The main economy of the region relies on the oil source, trade from neighboring countries and industry. Agriculture and tourism are also other main sources 
of income in this province. According to the Köppen-Geiger, climate classification system, Duhok has a borderline semi-arid (BSh) and Mediterranean climate (Csa) with extremely hot, dry summers and cold, wet winters. Precipitation falls in the cooler months, being heaviest in late winter and early spring. The province is covered by forest and high mountain.
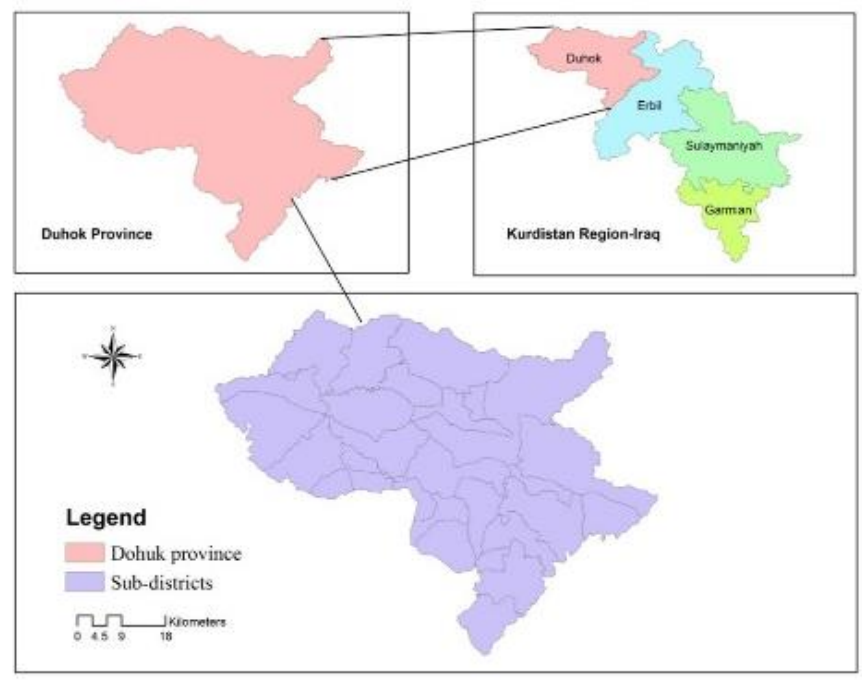

\section{METHOD}

\section{A. Criteria (Factors)}

In this research, we first reviewed similar studies to find the factors that affect the state of the environment. Then, based on the accessibility to the required data, population density, solid waste generation, and density of the industry (numbers of industry) were considered as affecting factors. The overall flowchart of the methodology as in Fig. 2.

\section{- Population density}

Population density (people per $\mathrm{km} 2$ ) is a critical factor that pressures the environment. It is a measurement of the number of people in an area. In his study, for evaluating the population density on environmental quality, first, the information of the population for each subdistrict was attained. Fig. 3. This information was converted to a GIS database. Then the areas of the subdistricts were calculated in ArcGIS software. By dividing population numbers by the area, the population density for each subdistrict and the whole province was calculated. The calculated population density then classified into four classes in which from class 1 to class 4, the density increase, meaning that the quality of the environment decrease.

Fig. 1:Case Study, Duhok Province

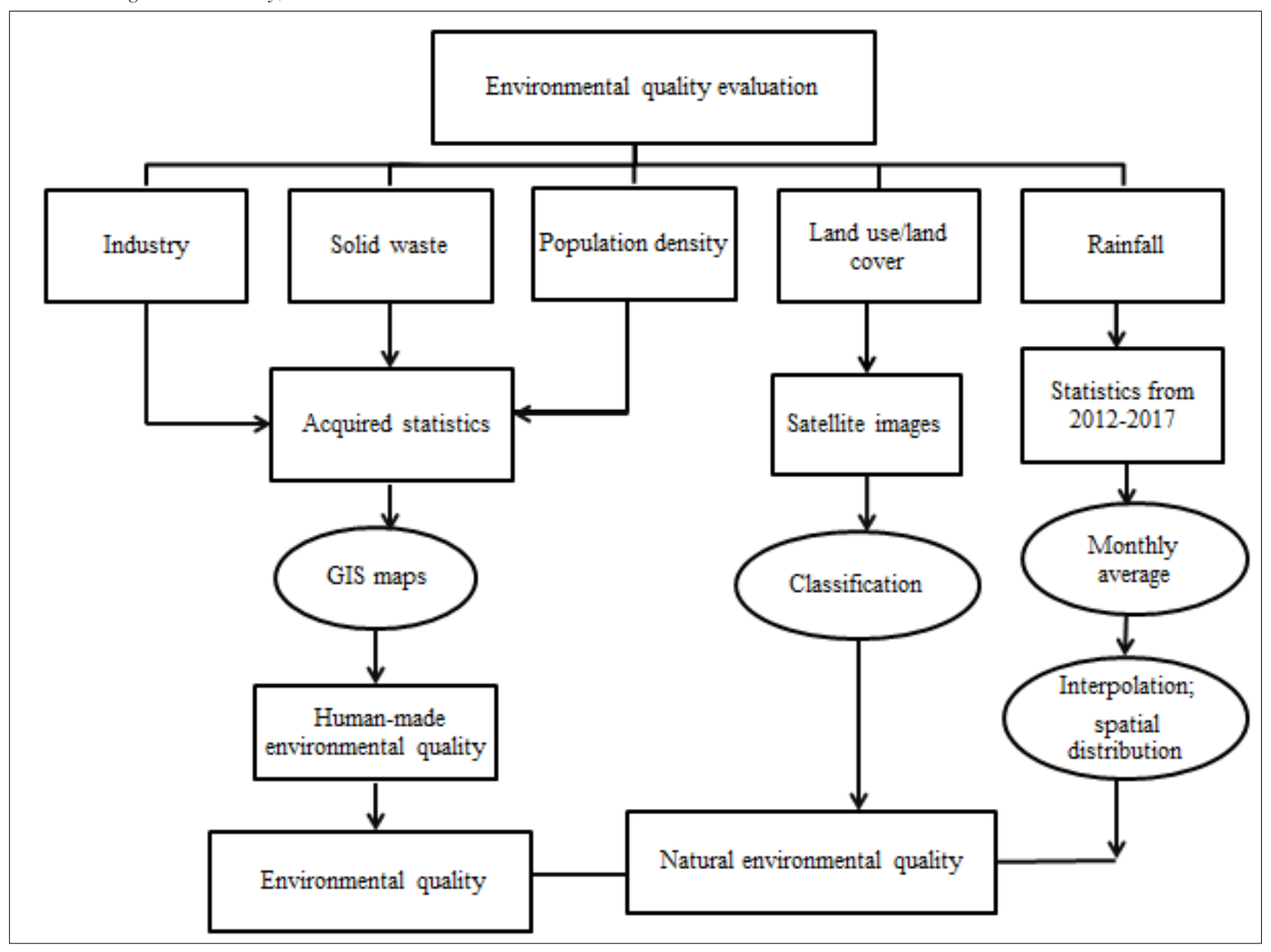

Fig 2: Flowchart of the methodology 


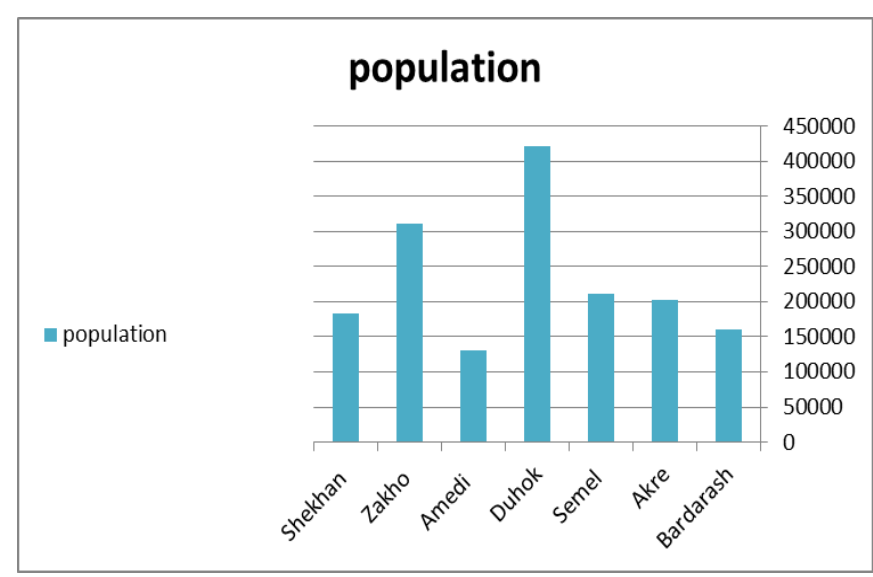

Fig. 3:Number of populations in Duhok province (Sources: 14)

\section{- $\quad$ Industry}

Industries are significant sources of environmental pollution. The areas with a high density of industrial units and industrial zones face a higher environmental pollution level. The number and locations of the industrial units of the Duhok province were attained from Duhok Environment Department (Fig. 4). The locations were converted to ArcGIS software, and the number of industries in each subdistrict was calculated. Then, the number of industries was classified into four classes, where class 1 to class 4 that class 1 has the lowest density, and class 4 has the highest density. From class 1 to 4 , the potential of environmental pollution increase, and the quality decrease.

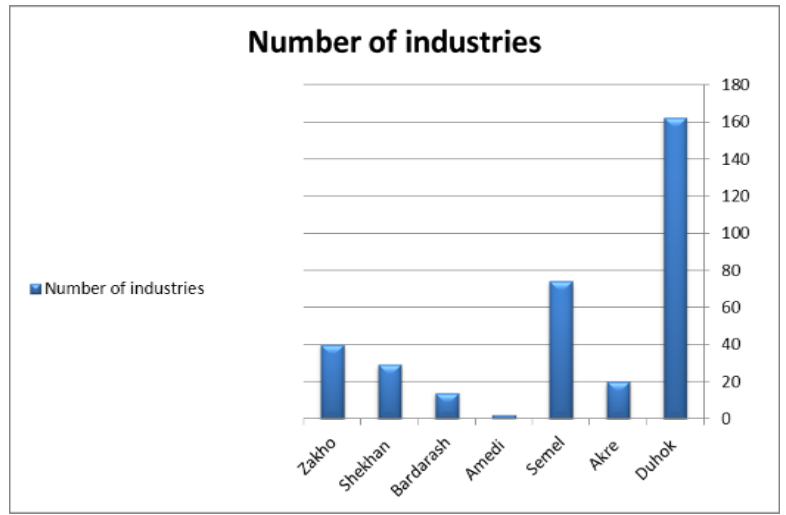

Fig. 4:Number of industries in Duhok province (Sources: 15)

\section{- $\quad$ Solid Waste}

Solid waste can create significant health problems and an unpleasant living environment in the lack of safe and proper management plans. Unfortunately, the solid waste in Duhok province is not managed efficiently as in other parts of the Kurdistan region. For calculating the solid waste in the total province and its sub-counties, the average rate of waste generation per person/day was attained from Duhok Municipality. As in Table I., the rate ranges from about 0.7 to $1.4 \mathrm{~kg}$ per person per day. Then, the rate of solid waste generation multiplied in the population number, and the solid waste generated in each county was calculated. The calculated waste classified into four classes in which from class 1 to class 4 , the volume of waste increase, meaning that the quality of the environment decrease.

TABLE 1. RATE OF SOLID WASTE GENERATION IN DUHOK PROVINCE [16]

\begin{tabular}{|l|l|}
\hline District & $\begin{array}{l}\text { Rate of waste generation } \\
\text { (person per kg per day ) }\end{array}$ \\
\hline Akre & 0.89 \\
\hline Amedy & 1.02 \\
\hline Bardarash & 0.8 \\
\hline Duhok & 1 \\
\hline Semel & 0.94 \\
\hline Shekhan & 1.33 \\
\hline Zakho & 1.27 \\
\hline
\end{tabular}

\section{B. Quality assessment}

Human-made factors evaluated in this study include population density, solid waste generation, and industry. As mentioned, these three factors were calculated for whole province maps and as small units for each county as well. The maps for factors were created in ArcGIS and aggregated to find the quality of the human environment human. Since the population directly relates to traffic and fuel consumption, the population density factor was assigned as in Table II. The map shows four levels, representing high quality (better), middle, low quality (bad), and very quality (worse), respectively.

TABLE 2: WEIGHT OF THE CRITERIA

\begin{tabular}{|l|l|}
\hline Human Factor & Weight (importance ) \\
\hline Population density & 0.5 \\
\hline Industry & 0.25 \\
\hline Solid waste generation & 0.25 \\
\hline
\end{tabular}

\section{RESULTS}

The quality of the human-made environment was attained by analyzing population density, industrial density, and solid waste generation. The maps of the factors were created and aggregated to show the final map. Fig. 5. the quality of the human-made environment in the province and as a small unit for subdistricts. The map was classified into four groups, including high (good), middle, low (bad), and very low (worse) quality. As in Table III and Fig. 5. the percent of the classes are shown. Overall, about $85 \%$ of the study area has moderate to high, while low and very low contribute to $13 \%$ and $1 \%$, respectively. 


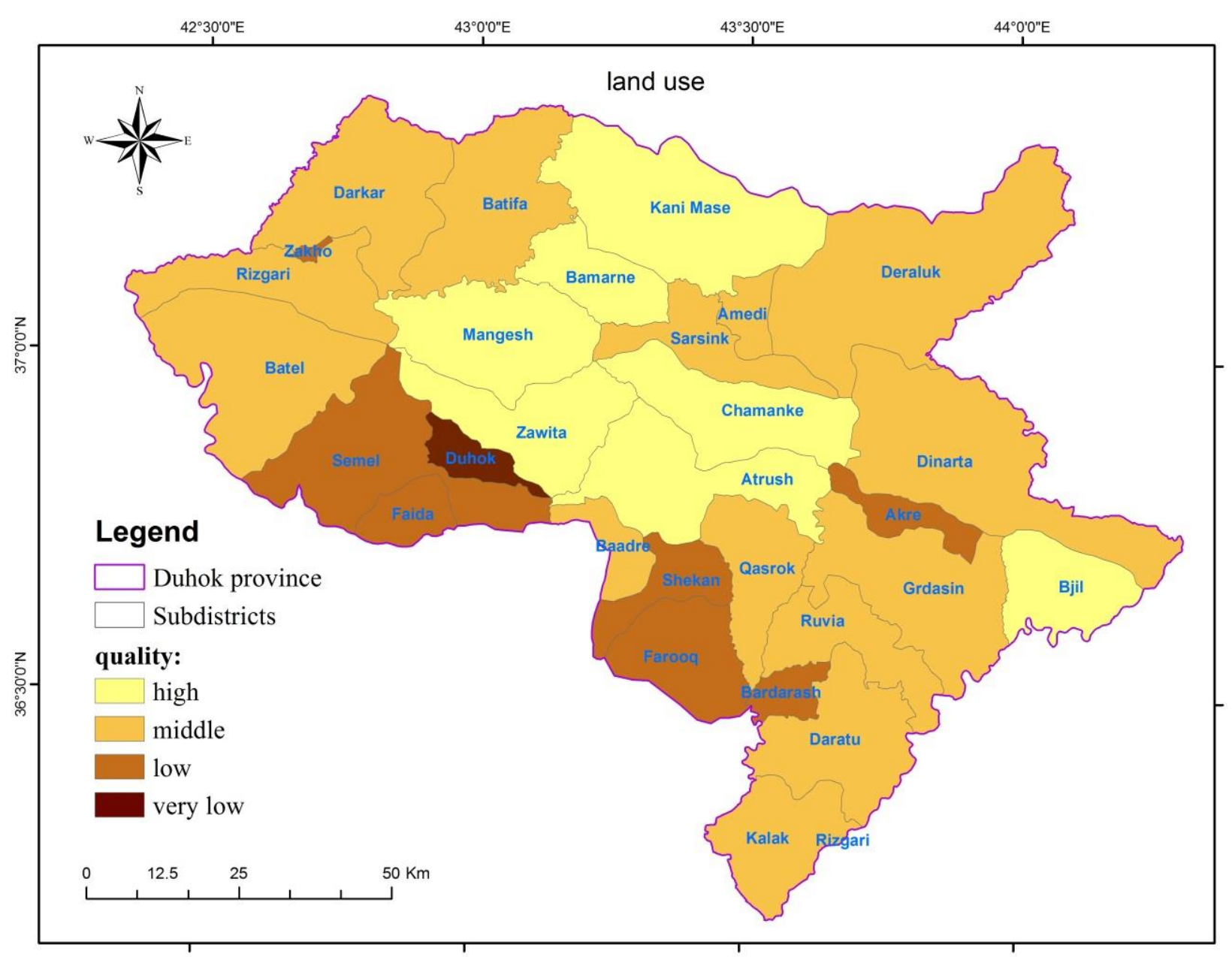

Fig. 5: Human-made quality of the environment in Duhok province

TABLE 3, PERCENTAGE AND AREA OF QUALITY CLASS

\begin{tabular}{|l|l|l|}
\hline Class (quality) & Area (percent) & Area (hectare) \\
\hline High & 28 & 3127 \\
\hline middle & 58 & 6355 \\
\hline low & 13 & 1415 \\
\hline Very low & 1 & 116 \\
\hline sum & 100 & 11013 \\
\hline
\end{tabular}

\section{DISCUSSION AND CONCLUSION}

Based on the analysis, the Duhok subdistrict has a worse situation since it is a densely-populated city in the province. Also, about half of the industries are located in this subdistrict. Other main cities such as Zakho, Shekhan, and Semel, located in the center subdistricts, have low quality meaning that the environment's pressure is somehow high. In general, northern and eastern parts have better quality than those areas located in the west and southwest. The overall results showed that most of the province has good environmental quality. However, the center of the province and other big cities contributed to the low level of quality. It also can be concluded that this province has a good situation in the aspect of the natural state. In contrast, human-made elements represented the reverse state. Unfortunately, while the industry has not been developed as in other countries, the rate of solid waste is high in the province. Also, the solid waste has not been treated efficiently or deposed safely. This makes this urgent situation that solid waste should be managed in the best way.

This research clearly showed the capability of GIS for spatial analysis and the efficiency of this technique compared to traditional methods. Using a province as a case study can potentially reveal the current state of regional environmental quality and could efficiently resolve the problems of regional problems. This research is a step towards future work on determining an environmental quality evaluation. It also is a framework to add new criteria such as natural risks and hazards, soil erosion, and also environmental pollution to characterize the accurate and precise situations of environmental quality. 


\section{ACKNOWLEDGMENT}

This paper is a report from a B.Sc final project. The authors thank the University of Zakho, Department of Environmental Science, for their support. We also express our appreciation to Duhok Environmental Department, Duhok Municipality, and Duhok Meteorology Organization.

\section{CONFLICT OF INTEREST}

The authors have no conflicts of interest.

\section{REFERENCES}

[1] A. Li, A. Wang, S. Liang, and W. Zhou, "eco-environmental vulnerability evaluation in the mountainous region using remote sensing and GIS - a case study in the upper reaches of Minjiang River, China," Ecol. Model., vol. 192, no. 1-2, pp. 175-187, 2006.

[2] G. Aad et al., "Observation of a new particle in the search for the Standard Model Higgs boson with the ATLAS detector at the LHC," Phys. Lett. B, vol. 716, no. 1, pp. 1-29, 2012.

[3] L. T. Tran, R. V. O'Neill, and E. R. Smith, "Spatial pattern of environmental vulnerability in the Mid-Atlantic region, USA," Appl. Geogr., vol. 30, no. 2, pp. 191-202, 2010.

[4] R. Aretano, T. Semeraro, I. Petrosillo, A. De Marco, M. R. Pasimeni, and G. Zurlini, "Mapping ecological vulnerability to fire for effective conservation management of natural protected areas," Ecol. Model., vol. 295, pp. 163-175, 2015.

[5] Y. Chen, J. Yu, and S. Khan, "Spatial sensitivity analysis of multicriteria weights in GIS-based land suitability evaluation," Environ. Model. Softw., vol. 25, no. 12, pp. 1582-1591, 2010.

[6] K. Schotten, R. Goetgeluk, M. Hilferink, P. Rietveld, and H. Scholten, "Residential construction, land use and the environment. Simulations for the Netherlands using a GIS-based land use model," Environ. Model. Assess., vol. 6, no. 2, pp. 133-143, 2001.

[7] H. Karimi, A. Soffianian, N. Mirghaffari, and S. Soltani, "Determining air pollution potential using geographic information systems and multicriteria evaluation: A case study in Isfahan province in Iran," Environ. Process., vol. 3, no. 1, pp. 229-246, 2016.

[8] H. Lan, C. Zhou, L. Wang, H. Zhang, and R. Li, "Landslide hazard spatial analysis and prediction using GIS in the Xiaojiang watershed, Yunnan, China," Eng. Geol., vol. 76, no. 1-2, pp. 109-128, 2004.

[9] A. J. Cohen et al., "Estimates and 25-year trends of the global burden of disease attributable to ambient air pollution: an analysis of data from the Global Burden of Diseases Study 2015," The Lancet, vol. 389, no. 10082, pp. 1907-1918, 2017.

[10] H. Karimi, J. Jafarnezhad, K. Khaledi,. et al. Monitoring and prediction of land use/land cover changes using CA-Markov model: a case study of Ravansar County in Iran. Arab J Geosci 11, 592 (2018). https://doi.org/10.1007/s12517-018-3940-5.

[11] A. Kourosh Niya,, J. Huang, H Karimi, H, H. Keshtkar, B Naimi. Use of Intensity Analysis to Characterize Land Use/Cover Change in the Biggest Island of Persian Gulf, Qeshm Island, Iran. Sustainability 2019, 11, 4396.

[12] Ali, S.A., Ahmad, A. Suitability analysis for municipal landfill site selection using fuzzy analytic hierarchy process and geospatial $\begin{array}{llll}\text { technique. Environ } & \text { Earth } & \text { Sci 79, } 227 & \end{array}$ https://doi.org/10.1007/s12665-020-08970-z

[13] H. Karimi, B. M. Herki, S. Q. Gardi, S. Galali, H. Hossini, K. Mirzaei \& M. Pirsaheb (2020) Site selection and environmental risks assessment of medical solid waste landfill for the City of KermanshahIran, International Journal of Environmental Health Research, DOI: 10.1080/09603123.2020.1742876

[14] Governorship of Duhok, 2019, Number of populations in Duhok province.
[15] Duhok Environment Department, 2019, number and locations of the industrial units.

[16] Duhok Municipality,2019, Rate of solid waste generation in Duhok province. 